\title{
Mechanistic and In silico Characterization of Metal ion Requirements of Escherichia coli Zinc Phosphodiesterase Activity
}

\author{
*Adedoyin Igunnu, Micheal F. Dada, Tamonokorite AbelJack-Soala, Ireoluwa Y. Joel, \\ Oluwafunmibi O. Lanre-Ogun, Oluwadamilola O. Opadeyi, Kelechi E. Okpara, George 0. \\ Ambrose and Sylvia 0 . Malomo
}

\begin{abstract}
Department of Biochemistry, Faculty of Life Sciences, University of Ilorin, Ilorin, Nigeria
\end{abstract}
Received $19^{\text {th }}$ February, 2020, Accepted $9^{\text {th }}$ June, 2020

DOI: 10.2478/ast-2020-0007

*Corresponding author

Adedoyin Igunnu, Ph.D.E-mail: doyinigunnu@unilorin.edu.ng

Tel: +234-8030707937

\section{Abstract}

Zinc phosphodiesterase (ZiPD) participates in the maturation of tRNA precursors. The roles of metal ions in promoting phosphoryl transfer reaction on zinc phosphodiesterase (ZiPD) activity have not been fully characterized. Therefore, this study investigated the effects of some metal ions on phosphodiesterase activity of Escherichia coli ZiPD as well as the binding site and binding affinity of the metal ions. ZiPD activity was measured by monitoring the rate of hydrolysis of bis-para-nitrophenyl phosphate (bis-pNPP) in the presence of some selected divalent metal ions $\left(\mathrm{Mn}^{2+}, \mathrm{Co}^{2+}, \mathrm{Mg}^{2+}\right.$ and $\mathrm{Zn}^{2+}$ ). The results obtained revealed that $\mathrm{Mn}^{2+}$ at $1 \mathrm{mM}$ activated ZiPD activity by 4 -fold with binding affinity score of $1.795 . \mathrm{Co}^{2+}$ at $0.5 \mathrm{mM}$ activated ZiPD activity by 2-fold with binding affinity score of 1.773. $\mathrm{Mg}^{2+}$ at $0.5 \mathrm{mM}$ enhanced the binding affinity of ZiPD for bis-pNPP but did not increase the turnover rate of $\mathrm{ZiPD}$. $\mathrm{Zn}^{2+}$ at $1.5 \mathrm{mM}$ activated ZiPD activity by 2 -fold via increased affinity of ZiPD for bis-pNPP. In conclusion, the findings from this study showed that $\mathrm{Mn}^{2+}$ and $\mathrm{Zn}^{2+}$ are the most effective stimulatory ions of ZiPD for bis-pNPP while $\mathrm{Zn}^{2+}$ exerted the highest binding affinity of ZiPD for bis-pNPP.

Keywords: Zinc phosphodiesterase; phosphodiesterase activity; binding affinity; metal ions 


\subsection{Introduction}

Phosphoryl transfer reactions are important phenomena in biological systems that require well-controlled mechanisms for the transfer of phosphate groups from donor molecules to molecules accepting the phosphate group. Enzymes that catalyse phosphoryl transfer reactions (phosphomonoesterases, phosphodiesterases and phosphotriesterases) employ metal ion cofactors as key participants in regulating their catalytic actions (Igunnu et al., 2014). Zinc phosphodiesterase (ZiPD) is a member of tRNase Z enzymes that belong to the family of metal dependent $\beta$-lactamases (Tavtigian et al., 2001), a group of metalloproteins which perform a variety of functions (Daiyasu et al., 2001). ZiPD is encoded by ElaC gene that is prevalent in eubacteria, archaebacteria, and mammals with a highly conserved sequence (Minagawa et al., 2004).

Most single tRNA molecules end with the 3 terminal sequence CCA (Minagawa, et al., 2006) which is necessary for aminoacylation of the tRNAs and for translation on the ribosome (Green and Noller, 1997). The tRNAs are transcribed as larger precursors, which subsequently undergo different processing steps such as removal of 5 and 3 extra nucleotides to produce mature tRNAs (Morl and Marchfelder, 2001). Specific Nucleases carry out a precise cleavage of precursor tRNA (pretRNA) after its transcription at both the 5 and 3 extensions which is a vital activity in the maturation of tRNA (Morl and Marchfelder, 2001). ZiPD participates in the maturation of tRNA precursors in both E. coli mutant strains without the 3-tRNA maturation exoribonucleases and in wild type E. coli strains (Dutta et al., 2012; Kelly and Deutscher, 1992). ZiPD exhibits both endoribonuclease and exoribonuclease activity. It functions as an exoribonuclease on tRNA precursors lacking a CCA sequence and acts as an endoribonuclease on tRNA precursors in which CCA sequence is present at the 3 terminal end (Dutta et al., 2012).

Zinc phosphodiesterase is a homodimeric enzyme containing two subunits with each monomer showing the typical metallo- $\beta$-lactamase fold (de la Sierra-Gallay et al., 2005), with a core of two-seven-strand $\beta$-sheets which are flanked on each side by $\alpha$-helices. The two sheets have similar topologies, consisting of four antiparallel $\beta$-strands followed by three parallel $\beta$-strands. There is an exosite which extends from the body of the protein between $\beta$-strands $\beta 9$ and $\beta 12$. The

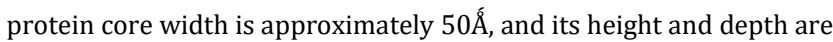

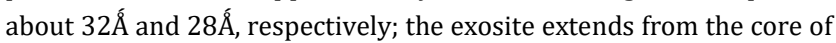
the protein at a slight angle and has a total length of approximately $40 \AA$ (Vogel et al., 2004; de la Sierra-Gallay et al., 2005). The ZiPD dimerization interface is in the region of helices $\alpha 1, \alpha 2$, and $\alpha 3$, and the dimer is arranged with the monomers in a head-to-head fashion with the exosite tails extending away from each other. A narrow cleft is formed jointly by the two monomers in which the active site and metal coordination residues are present (Dutta and Deutscher, 2009). Furthermore, another narrow cleft corresponding to the proposed 3' trailer RNA binding channel of the $B$. subtilis tRNase $\mathrm{Z}$ enzyme (de la Sierra-Gallay et al., 2005) is positioned directly adjacent to this active site cleft and is formed by a single monomer using the loop between $\alpha 3$ and $\beta 6$ and several residues from the $\alpha 2$ helix.
Zinc phosphodiesterase exhibits a binuclear metal binding site (Daiyasu et al., 2001). The metal coordination sites of the structurally characterized members of this enzyme family are identified partly by residues from the conserved sequence motif $\mathrm{H} X \mathrm{H} X \mathrm{DH}$ (Vogel et al., 2005). In general, metallo- $\beta$-lactamases bind one or two metal ions, preferably zinc, iron, or manganese with high selectivity (Vogel, 2002). These metal ions are essential for numerous biocatalytic processes and also to achieve catalytic functionality. Although the monomers of ZiPD have a binuclear metal binding site, the roles of metal ions in promoting phosphoryl transfer catalysed by ZiPD are yet to be fully understood. Therefore, this study investigated the effects of some metal ions on the E. coli ZiPD activity as well as the binding site and binding affinity of the metal ions with the view to gaining further insight into the metabolic function of metal ions in ZiPD catalysis.

\subsection{Experimental}

\section{Materials}

Bis-para-nitrophenyl phosphate (bis-pNPP) was a product of SigmaAldrich, UK. Purified homogenous Escherichia coli zinc phosphodiesterase (ZiPD) was obtained from the Institute of Molecular Cell and Systems Biology, University of Glasgow, UK. All other chemicals used were of analytical grade.

\section{Determination of E. coli Zinc Phosphodiesterase Catalyzed Hydrolysis of Bis-para-nitrophenyl Phosphate}

Phosphodiesterase activities of ZiPD were measured by the rate of hydrolysis of bis-pNPP by the modification of the method of Dutta et al. (2012) in the presence of divalent metal ions $\mathrm{Mn}^{2+}, \mathrm{Co}^{2+}, \mathrm{Mg}^{2+}$ and $\mathrm{Zn}^{2+}$ ) at $25^{\circ} \mathrm{C}$ in $0.1 \mathrm{M}$ Tris buffer, $\mathrm{pH}$ 7.5. The rate of appearance of para-nitrophenol was measured spectrophotometrically and enzyme activity was expressed as the change in absorbance per minute. Reaction mixture containing ZiPD and buffers in the presence of the appropriate ligand at specific concentrations was pre-incubated at $25^{\circ} \mathrm{C}$ for 10 minutes. Reaction was initiated by the addition of the appropriate concentrations of the substrate for 15 minutes, and stopped by the addition of $0.5 \mathrm{M} \mathrm{KOH}$. The absorbance was read at $405 \mathrm{~nm}$ against a blank of the buffered substrate for bis-pNPP hydrolysis. Spectrophotometric readings were taken on a visible spectrophotometer. All measurements of reaction rate were carried out in triplicates and average was taken. Activities are expressed as change in $\mathrm{A}_{405}$ per minute reflecting the release of para-nitrophenol from the substrate bis-para-nitrophenyl phosphate (bis-pNPP).

\section{Effects of Ligands on E. coli Zinc Phosphodiesterase Activity}

In order to investigate the concentration dependent effects of the metal ions $\left(\mathrm{Mn}^{2+}, \mathrm{Co}^{2+}, \mathrm{Mg}^{2+}, \mathrm{Zn}^{2+}\right)$ on the phosphodiesterase activities of ZiPD, aliquots of $20 \mu \mathrm{L}$ of $1.25 \mu \mathrm{M}$ ZiPD were pre- incubated with varying concentrations $(0-3000 \mu \mathrm{M})$ of the individual ligands in $0.1 \mathrm{M}$ Tris buffer at $25^{\circ} \mathrm{C}$ for 10 minutes to ensure binding to the metal ion sites of the enzyme. Reaction was initiated by the addition of $(50 \mu \mathrm{L}$ of $5 \mathrm{mM}$ ) bis-pNPP to the reaction mixture for 15 minutes and stopped by the addition of $500 \mu \mathrm{L} 0.5 \mathrm{M} \mathrm{KOH}$ as previously described (Dutta et al., (2012). 
Effect of Ligands on Kinetic Parameters of E. coli Zinc Phosphodiesterase Activity

In order to investigate the effects of the metal ions $\mathrm{CMn}^{2+}, \mathrm{Co}^{2+}, \mathrm{Mg}^{2+}$, $\mathrm{Zn}^{2+}$ ) on the substrate kinetics of ZiPD, aliquots of $20 \mu \mathrm{L}$ of $1.25 \mu \mathrm{M}$ ZiPD were pre-incubated with specific concentrations of the ligands $\left(1000 \mu \mathrm{M} \mathrm{Mn}^{2+}\right.$ or $500 \mu \mathrm{M} \mathrm{Co}^{2+}$ or $500 \mu \mathrm{M} \mathrm{Mg}^{2+}$ or $\left.1500 \mu \mathrm{M} \mathrm{Zn}^{2+}\right)$ in 0.1 $\mathrm{M}$ Tris buffer at $25^{\circ} \mathrm{C}$ for 10 minutes to ensure binding to the metal ion sites of the enzyme. Reaction was initiated by the addition of varying concentrations of substrate $(100-2000 \mu \mathrm{M})$ to the reaction mixture for 15 minutes and stopped by the addition of $500 \mu \mathrm{L} 0.5 \mathrm{M} \mathrm{KOH}$ as previously described (Dutta et al., (2012). The data were fitted to the Michaelis-Menten curve and Lineweaver-Burk plot using Microsoft Excel and kinetic constants $\left(\mathrm{V}_{\max }\right.$ and $\left.\mathrm{K}_{\mathrm{m}}\right)$ were obtained.

\section{Accession and Preparation of 3D Structure of Zinc Phosphodiesterase}

The protein, Escherichia coli zinc phosphodiesterase (ZiPD) was prepared by retrieving the three-dimension crystal structure of ZiPD, (PDB ID: 2CBN) from RCSB PDB (http://www.rcsb.org $\angle \mathrm{pdb} /$ home/home.do). The bound complex molecules with the proteins were removed. The non-essential water molecules and all heteroatoms were removed using Pymol tool and Discovery studio 2017R2 respectively.

\section{Metal Ion Binding based on Fragment Transformation Method}

Metal ion binding (MIB) is a binding sites prediction server for metal ions, and this server provides an accurate, integrated method to search the residues in metal ion-binding sites by using the fragment transformation method (Chih-Hao et al., 2012). $\mathrm{Mn}^{2+}, \mathrm{Co}^{2+}, \mathrm{Mg}^{2+}$ and $\mathrm{Zn}^{2+}$ binding to ZiPD were predicted following the MIB workflow (Figure 1)

\section{Visualization of Molecular Docked Complexes}

After the binding sites prediction of the metal ions was carried out, docking of $\mathrm{Mn}^{2+}, \mathrm{Co}^{2+}, \mathrm{Mg}^{2+}$ and $\mathrm{Zn}^{2+}$ was performed using the MIB server and the docked complexes were visualized using the Pymol graphical interphase.

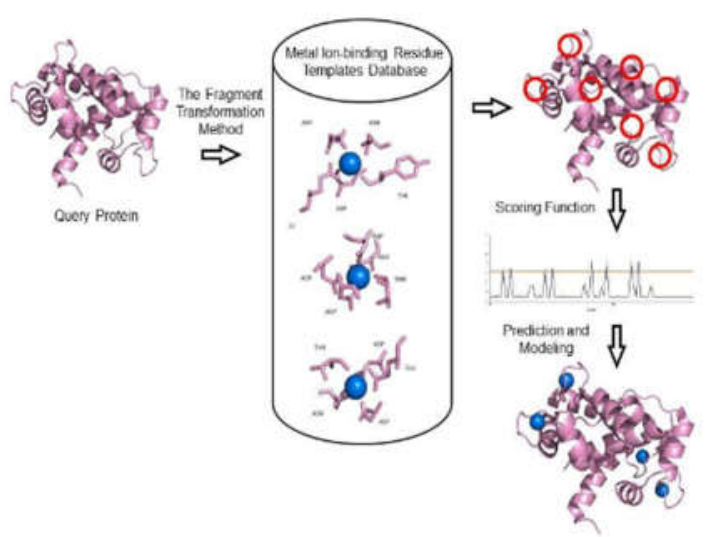

Figure 1: Metal-ion Binding workflow. This combines both structural and sequence information to identify the local structure of proteinmetal interaction sites (Chih-Hao et al., 2012)

\subsection{Results and Discussion}

Zinc phosphodiesterase has been established to be a binuclear zinc enzyme that hydrolyses phosphodiester bonds present in biomolecules; naturally occurring phosphodiesters includes nucleic acids and phospholipids. Assaying for this diesterase activity in the presence of zinc and other physiological divalent cations involves monitoring the rate at which it hydrolyzes bis-para-nitrophenyl phosphate (bis-pNPP) into para-nitrophenol.

\section{Activation Effect and Binding Potential of $\mathrm{Mn}^{2+}$ on E. coli Zinc Phosphodiesterase Activity}

In this study, the effect of varying concentrations of $\mathrm{Mn}^{2+}$ on E. coli ZiPD catalysed hydrolysis of bis-pNPP was investigated. $\mathrm{Mn}^{2+}$ increased ZiPD activity progressively from $200 \mu \mathrm{M}$ to $1000 \mu \mathrm{M}$, being the optimal concentration for ZiPD activity (Figure 2). There was 3-fold increase in ZiPD activity at this optimal concentration. This optimal activity of ZiPD was sustained from $1000 \mu \mathrm{M}$ to $2000 \mu \mathrm{M}$ concentrations of $\mathrm{Mn}^{2+}$. However, there was a decrease in the activation effect at $3000 \mu \mathrm{M} \mathrm{Mn}^{2+}$ (Figure 2). The Michealis-Menten curve and the Lineweaver-Burk plot for the substrate kinetics of ZiPD catalysed bis-pNPP hydrolysis both in the presence and absence of $\mathrm{Mn}^{2+}$ are shown in Figures $3 \mathrm{a}$ and $3 \mathrm{~b}$, respectively. $\mathrm{Mn}^{2+}$ at $1000 \mu \mathrm{M}$ increased the $\mathrm{V}_{\max }$ by 5 -fold but slightly decreased the $\mathrm{K}_{\mathrm{m}}$ (Table 1).

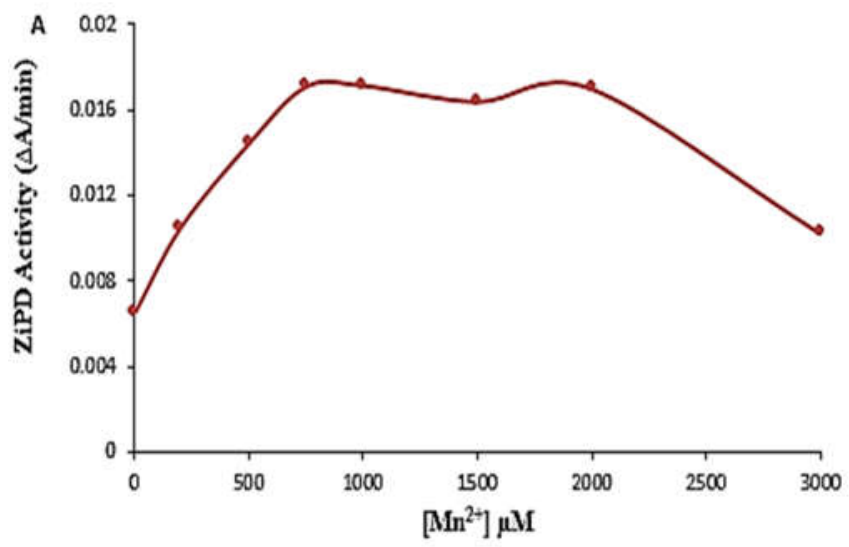

Figure 2: Activatory effect of $\mathrm{Mn}^{2+}$ on ZiPD catalysed hydrolysis of bispara-nitrophenyl phosphate. Each value is a mean of three independent assays.

Furthermore, the binding affinity of each of the residues was calculated against $\mathrm{Mn}^{2+}$ and only residues with higher binding scores are predicted as $\mathrm{Mn}^{2+}$ binding residues as shown in the Figure 4a while the affinity binding of $\mathrm{Mn}^{2+}$ within the predicted $\mathrm{Mn}^{2+}$ binding sites reveals the interacting residues at optimum binding (Figure 4b).

$\mathrm{Mn}^{2+}$ enhances the hydrolytic activity of metalloenzymes and also participates in nucleic acid interaction (Shumilina et al., 2014; Satya, 2018). The content of transition metals such as copper and manganese in ZiPD is negligible (Spath, et al., 2007) but in this study, the activation effect of $\mathrm{Mn}^{2+}$ on ZiPD activity could be due to the increased turnover rate and enhanced binding affinity of the enzyme for bis-pNPP which is indicated by the increased $V_{\max }$ and decreased $K_{m}$, respectively. This might be due to the way $\mathrm{Mn}^{2+}$ binds to ZiPD by interacting with ARG 
259 and GLU 260 which are present within the predicted binding sites as shown in Figure $4 \mathrm{~b}$. This $\mathrm{Mn}^{2+}$ coordinates additional water molecule that can be deprotonated by GLU-260 which in turn serves a nucleophile that attacks the phosphate group present on the substrate. Numerous amino acids have high binding potential for $\mathrm{Mn}^{2+}$ (Figure 4a) with $\mathrm{Mn}^{2+}$ having a binding affinity of 1.795 , so it may be that the binding of $\mathrm{Mn}^{2+}$ to the enzyme at any of this amino acid residues alters its conformation that makes the enzyme to bind more tightly to the substrate which then leads to enhanced catalytic rate. This observation is in line with the report of Shumilina et al. (2014) that bis-pNPP hydrolysis is enhanced in the presence of $\mathrm{Mn}^{2+}$. $\mathrm{Mn}^{2+}$ was the most effective cation stimulating ZiPD activity as observed in this study.
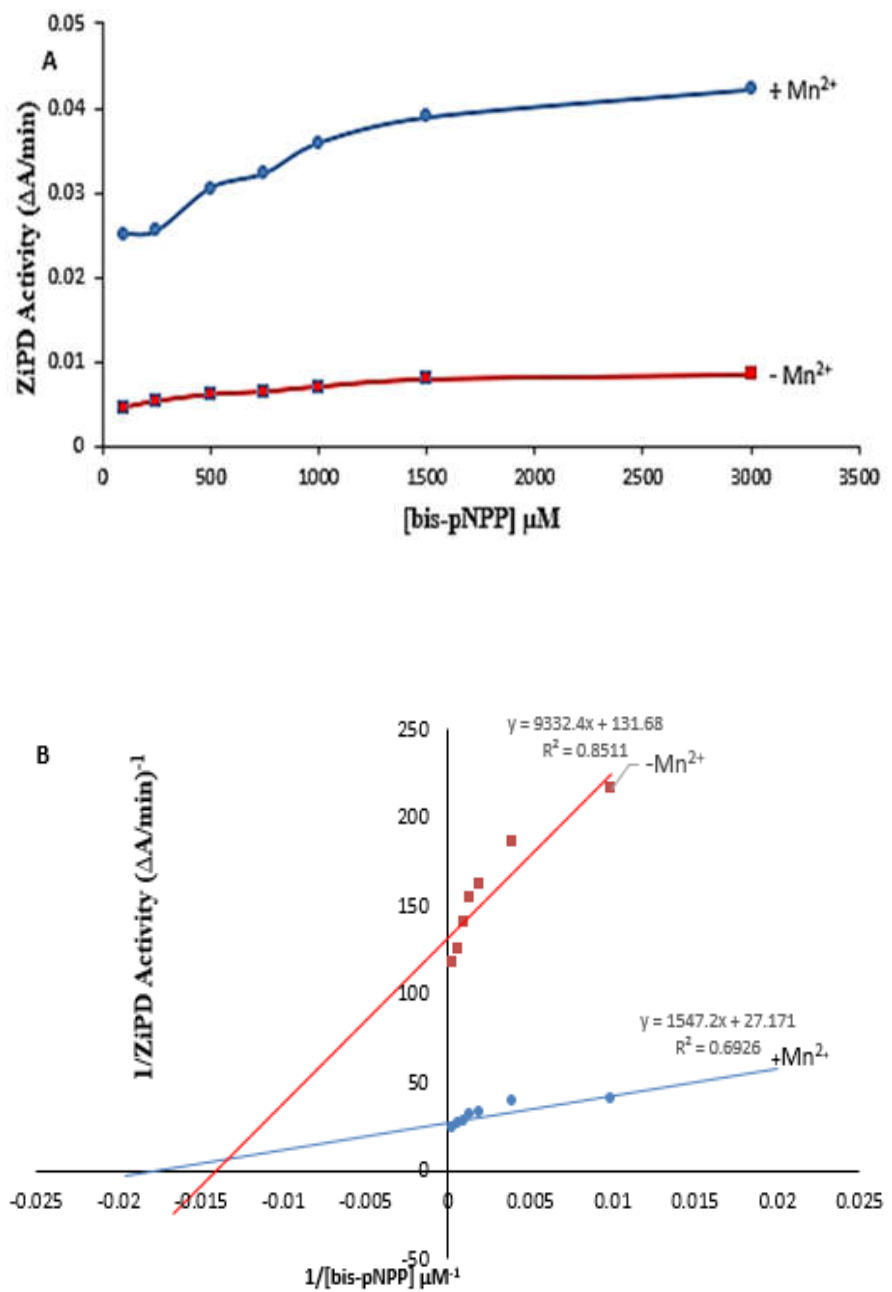

Figure 3: Substrate Kinetics of Zinc Phosphodiesterase catalysed Hydrolysis of bis-para-nitrophenyl phosphate (bis-pNPP) in the presence and absence of Manganese ion. (a) Michealis-Menten curve (b) Lineweaver-Burk plot. Each value is a mean of three independent assays.
Table 1: Kinetic parameters for $E$. coli zinc phosphodiesterase catalyzed hydrolysis of bis-para-nitrophenyl phosphate (bis-pNPP) in the absence and presence of $1 \mathrm{mM}$ of $\mathrm{Mn}^{2+}$ ion

\begin{tabular}{lcc}
\hline Reaction & $\mathbf{V}_{\max }(\boldsymbol{\Delta} \mathbf{A} / \mathbf{m i n})$ & $\mathbf{K}_{\mathbf{m}}(\boldsymbol{\mu} \mathbf{M})$ \\
\hline ZiPD- bis-pNPP & 0.007708 & 69.10 \\
ZiPD- bis-pNPP + 1 $\mathrm{mM} \mathrm{Mn}^{2+}$ & 0.037730 & 53.65 \\
\hline
\end{tabular}

A
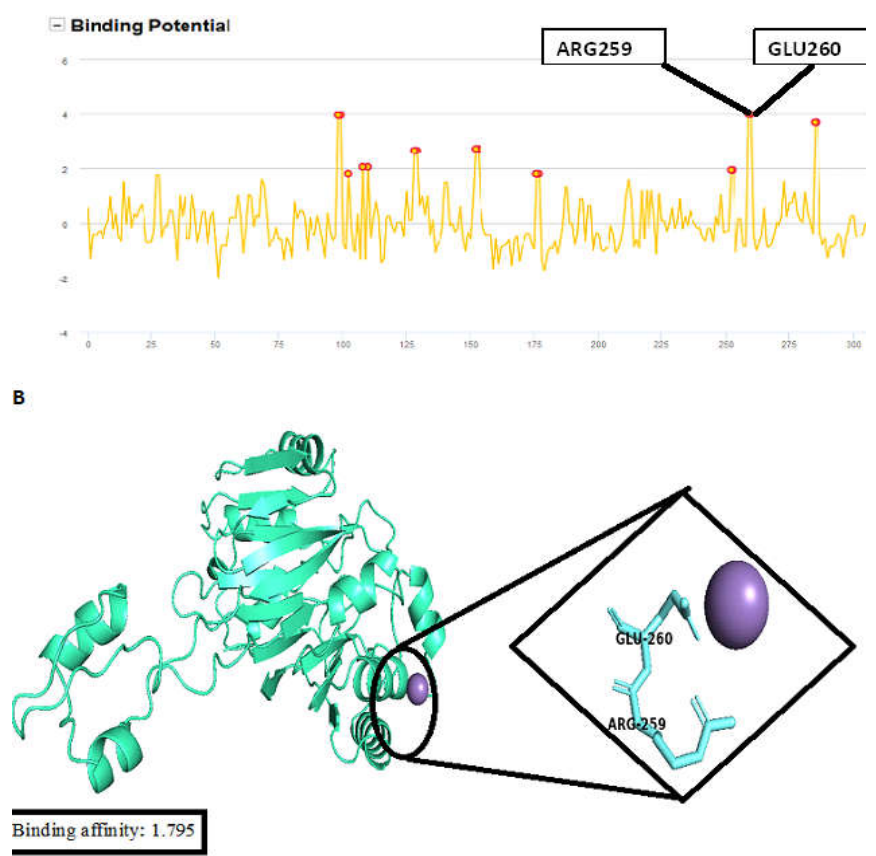

Figure 4: (a) Binding potential of each amino acid residues of ZiPD for $\mathrm{Mn}^{2+}$ and their corresponding binding affinities (b) Interacting residues within $\mathrm{ZiPD} \mathrm{Mn}^{2+}$ binding site with the corresponding binding potential

\section{Activation Effect and Binding Potential of $\mathrm{Co}^{2+}$ on E. coli Zinc Phosphodiesterase Activity}

The effect of varying concentrations of $\mathrm{Co}^{2+}$ on $E$. coli zinc phosphodiesterase (ZiPD) catalysed hydrolysis of bis-(paranitrophenyl) phosphate (bis-pNPP) was investigated. $\mathrm{Co}^{2+}$ increased ZiPD activity progressively from $200 \mu \mathrm{M}$ to $500 \mu \mathrm{M}$, being the optimal concentration for ZiPD activity (Figure 5). There was 2-fold increase in ZiPD activity at this optimal concentration. This optimal activity of ZiPD was sustained from $500 \mu \mathrm{M}$ to $1000 \mu \mathrm{M}$ concentrations of $\mathrm{Co}^{2+}$. However, there was a slight decrease in the activation effect from 1000 $\mu \mathrm{M}$ to $2000 \mu \mathrm{M} \mathrm{Co}^{2+}$ concentrations with a rise in activity at $3000 \mu \mathrm{M}$ (Figure 5). The Michealis-Menten curve and the Lineweaver-Burk plot for the substrate kinetics of ZiPD catalysed bis-pNPP hydrolysis both in the presence and absence of $\mathrm{Co}^{2+}$ are shown in Figures $6 \mathrm{a}$ and $6 \mathrm{~b}$, respectively. $\mathrm{Co}^{2+}$ at $500 \mu \mathrm{M}$ increased the $\mathrm{V}_{\max }$ and $\mathrm{K}_{\mathrm{m}}$ by 2 -fold and 2.5-fold, respectively (Table 2).

As consequence of the increased activity of ZiPD in the presence of $\mathrm{Co}^{2+}$, the binding affinity of each of the residues was calculated against $\mathrm{Co}^{2+}$ and only residues with higher binding scores are predicted as $\mathrm{Co}^{2+}$ 
binding residues as shown in Figure 7a while the binding affinity of $\mathrm{Co}^{2+}$ within the predicted $\mathrm{Co}^{2+}$ binding sites reveals the interacting residues at optimum binding (Figure $7 \mathrm{~b}$ ).

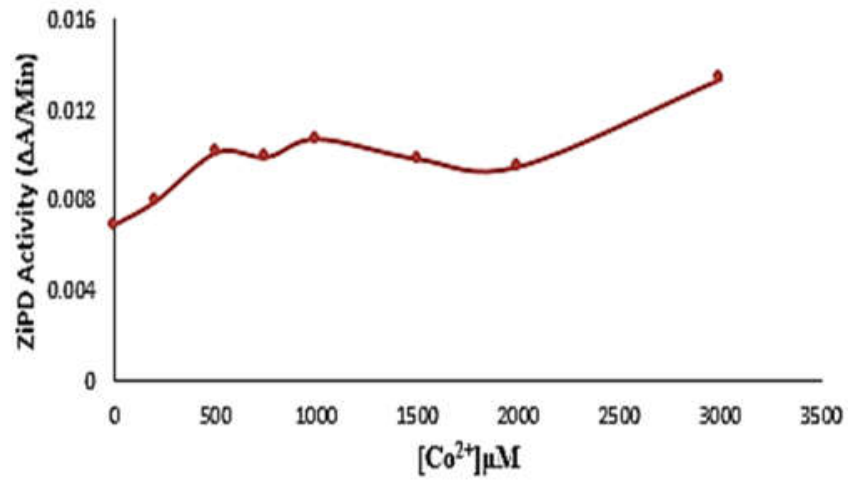

Figure 5: Activatory Effect of $\mathrm{Co}^{2+}$ on ZiPD catalysed hydrolysis of bispara-nitrophenyl phosphate. Each value is a mean of three independent assays.
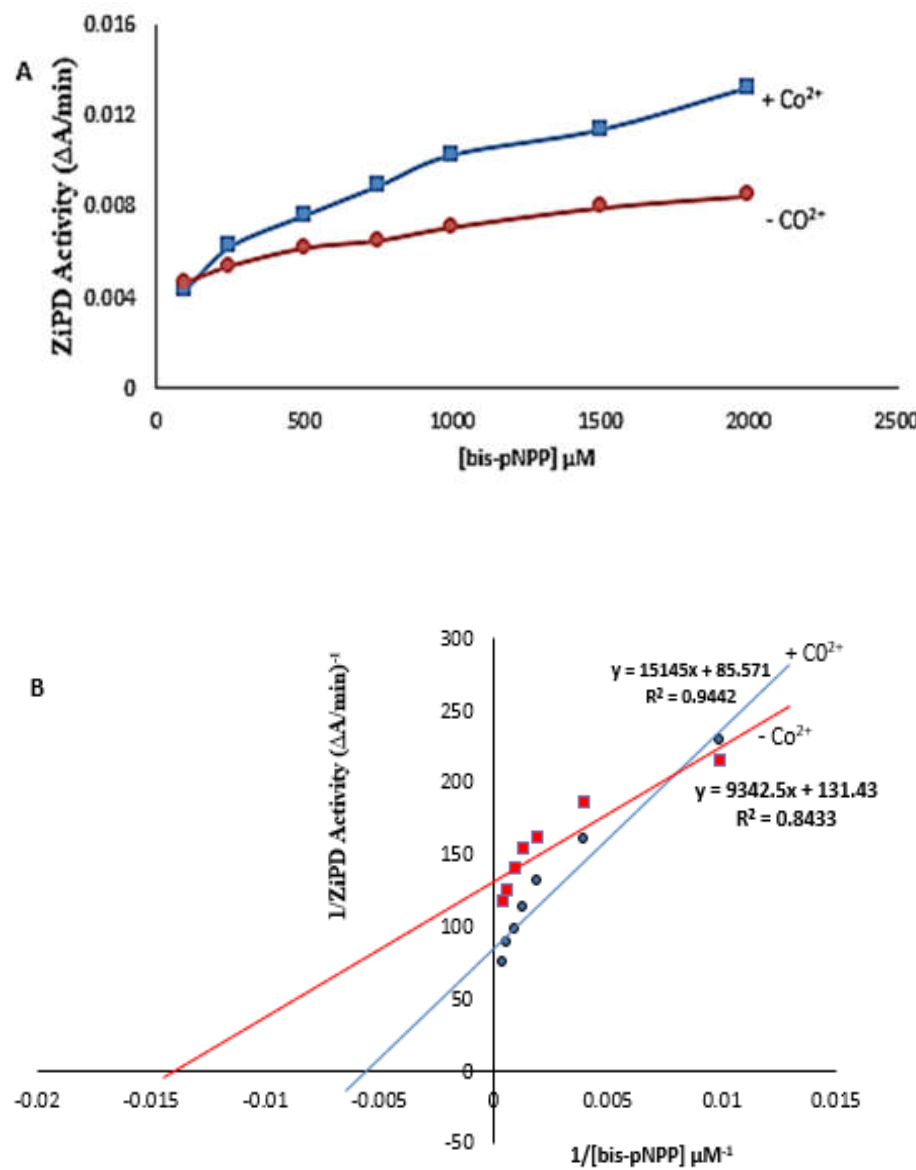

Figure 6: Substrate Kinetics of Zinc Phosphodiesterase catalysed Hydrolysis of bis-para-nitrophenyl phosphate (Bis-pNPP) in the presence and absence of $\mathrm{Co}^{2+}$ (a) Michealis-Menten curve (b) Lineweaver-Burk plot. Each value is a mean of three independent assays.
Table 2: Kinetic parameters for $E$. coli zinc phosphodiesterase catalyzed hydrolysis of bis-para-nitrophenyl phosphate (bis-pNPP) in the absence and presence of $0.5 \mathrm{mM}$ of $\mathrm{Co}^{2+}$ ion

\begin{tabular}{lcc}
\hline Reaction & $\mathbf{V}_{\max }(\boldsymbol{\Delta} \mathbf{A} / \mathbf{m i n})$ & $\mathbf{K}_{\mathbf{m}}(\boldsymbol{\mu} \mathbf{M})$ \\
\hline ZiPD-bis-pNPP & 0.007594 & 70.87 \\
ZiPD-bis-pNPP + 0.5 $\mathrm{mM} \mathrm{Co}^{2+}$ & 0.011620 & 175.45 \\
\hline
\end{tabular}
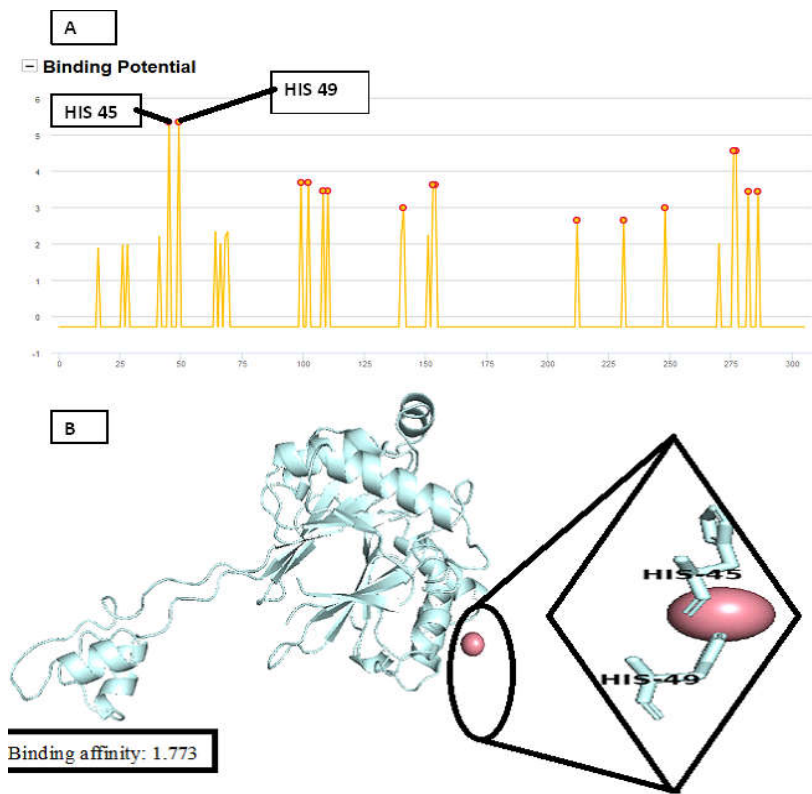

Figure 7: (a) Binding potential of each amino acid residues of ZiPD for $\mathrm{Co}^{2+}$ and their corresponding binding affinities (b) Interacting residues within $\mathrm{ZiPD} \mathrm{Co}^{2+}$ binding site with the corresponding binding potential

$\mathrm{Co}^{2+}$ ion is found almost exclusively in $\mathrm{B}_{12}$-dependent enzymes and is essential in maintaining the structure, function and stability of metalloenzymes (Jaishankar et al., 2014; Singh and Verma, 2018). In this study, there was an increase in the phosphodiesterase activity of ZiPD in the presence of $\mathrm{Co}^{2+}$ as indicated by an increase in $\mathrm{V}_{\max }$ (Figure 6). Less amino acid residues have potentials of binding to $\mathrm{Co}^{2+}$ ions but those that are capable have relatively higher binding potential (1.773); this increase might be as a result of the ability of the $\mathrm{Co}^{2+}$ ion to bind to sites other than the active sites which either leads to a conformational change or helps to coordinate more water molecules. This might be the reason why the presence of $\mathrm{Co}^{2+}$, strongly favors the exoribonucleolytic activity of ZiPD as reported by (Dutta et al., 2012). The increase in the $K_{m}$ might be due to the displacement of the binuclear $\mathrm{Zn}^{2+}$ by $\mathrm{Co}^{2+}$ since its lower in the electrochemical series; this binuclear $\mathrm{Zn}^{2+}$ (at HIS-248 and HIS-270) is responsible for the coordination of the substrate and the cooperativity of ZiPD. $\mathrm{Co}^{2+}$ and $\mathrm{Mn}^{2+}$ ions were observed to be the most efficient in stimulating activity against bis- $p$-nitrophenyl phosphate. This corresponds to the findings of Arise et al. (2008) that $\mathrm{Co}^{2+}$ is the preferred cation, both for phosphodiesterase activity and for action on RNA. 
Activation Effect and Binding Potential of $\mathrm{Mg}^{2+}$ on E. coli Zinc Phosphodiesterase Activity

The effect of varying concentrations of $\mathrm{Mg}^{2+}$ on E. coli zinc phosphodiesterase (ZiPD) catalysed hydrolysis of bis-paranitrophenyl phosphate (bis-pNPP) was investigated. $\mathrm{Mg}^{2+}$ increased ZiPD activity progressively from $200 \mu \mathrm{M}$ to $500 \mu \mathrm{M}$, being the optimal concentration for ZiPD activity (Figure 8). There was a fold increase in ZiPD activity at this optimal concentration. Furthermore, there was a progressive decrease in the activation effect from $500 \mu \mathrm{M}$ to $1500 \mu \mathrm{M}$ $\mathrm{Mg}^{2+}$ concentrations. However, there was an increased activity at 2000 $\mu \mathrm{M}$ concentration (Figure 8). The Michealis-Menten curve and the Lineweaver-Burk plot for the substrate kinetics of ZiPD catalysed bispNPP hydrolysis both in the presence and absence of $\mathrm{Mg}^{2+}$ are shown in Figures 9a and 9b, respectively. $\mathrm{Mg}^{2+}$ at $500 \mu \mathrm{M}$ slightly reduced the $\mathrm{V}_{\max }$ and also decreased the $\mathrm{K}_{\mathrm{m}}$ (Table 3).

The binding affinity of each of the residues was calculated against $\mathrm{Mg}^{2+}$ and only residues with higher binding scores are predicted as $\mathrm{Mg}^{2+}$ binding residues as shown in the Figure 10a while the affinity binding of $\mathrm{Mg}^{2+}$ within the predicted $\mathrm{Mg}^{2+}$ binding sites reveals the interacting residues at optimum binding (Figure 10b).

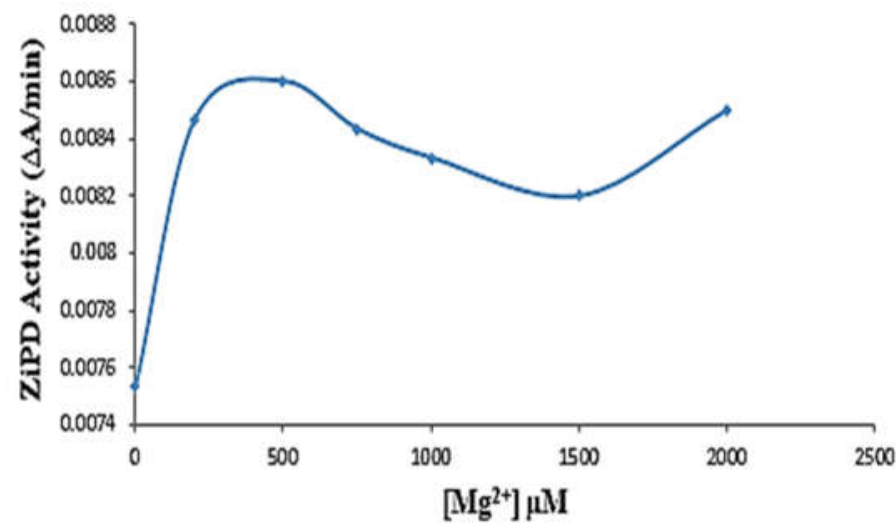

Figure 8: Activatory effect of $\mathrm{Mg}^{2+}$ on E. coli zinc phosphodiesterase catalysed hydrolysis of bis-para-nitrophenyl phosphate. Each value is a mean of three independent assays.

A

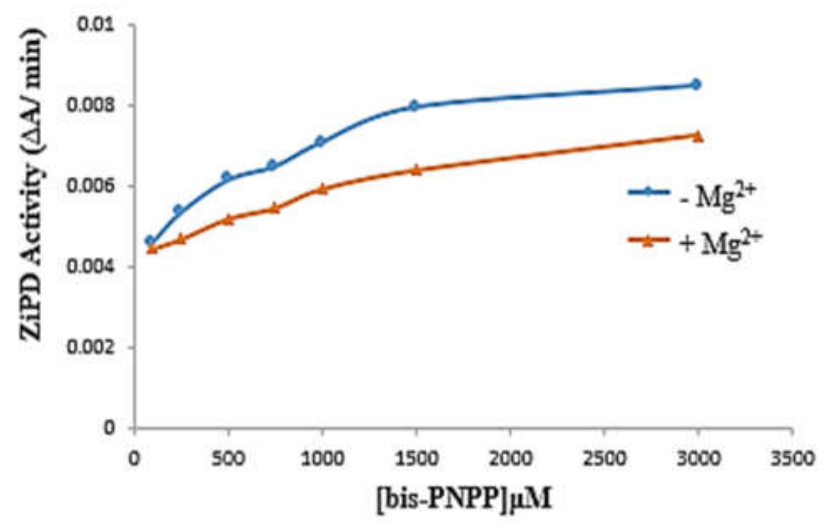

B

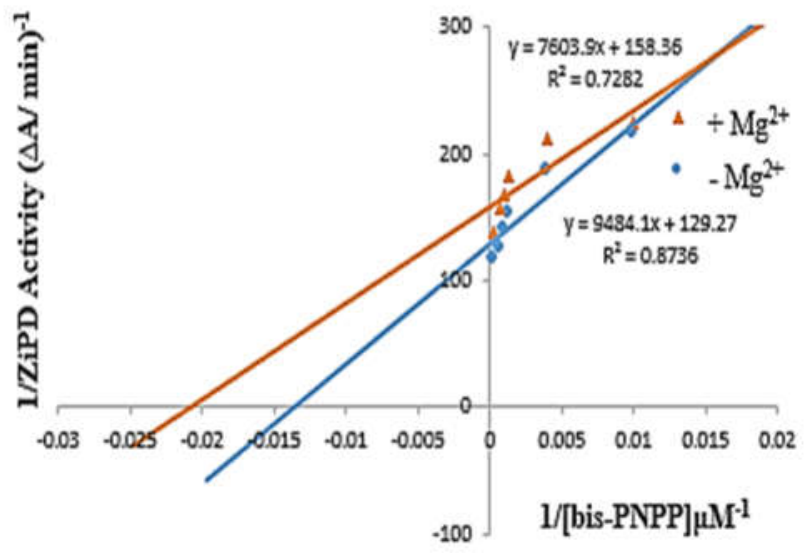

Figure 9: Substrate Kinetics of Zinc Phosphodiesterase catalysed Hydrolysis of bis-para-nitrophenyl phosphate (Bis-pNPP) in the presence and absence of $\mathrm{Mg}^{2+}$ (a) Michealis-Menten curve (b) Lineweaver-Burk plot. Each value is a mean of three independent assays.

Table 3: Kinetic parameters for E. coli zinc phosphodiesterase catalyzed hydrolysis of bis-para-nitrophenyl phosphate (bis-pNPP) in the absence and presence of $0.5 \mathrm{mM}$ of $\mathrm{Mg}^{2+}$

\begin{tabular}{lcc}
\hline Reaction & $\mathbf{V}_{\max }(\boldsymbol{\Delta} \mathbf{A} / \mathbf{m i n})$ & $\mathbf{K}_{\mathbf{m}}(\boldsymbol{\mu} \mathbf{M})$ \\
\hline ZiPD- bis-pNPP & 0.007736 & 73.37 \\
ZiPD- bis-pNPP $+0.5 \mathrm{mM} \mathrm{Mg}{ }^{2+}$ & 0.006315 & 48.02 \\
\hline
\end{tabular}
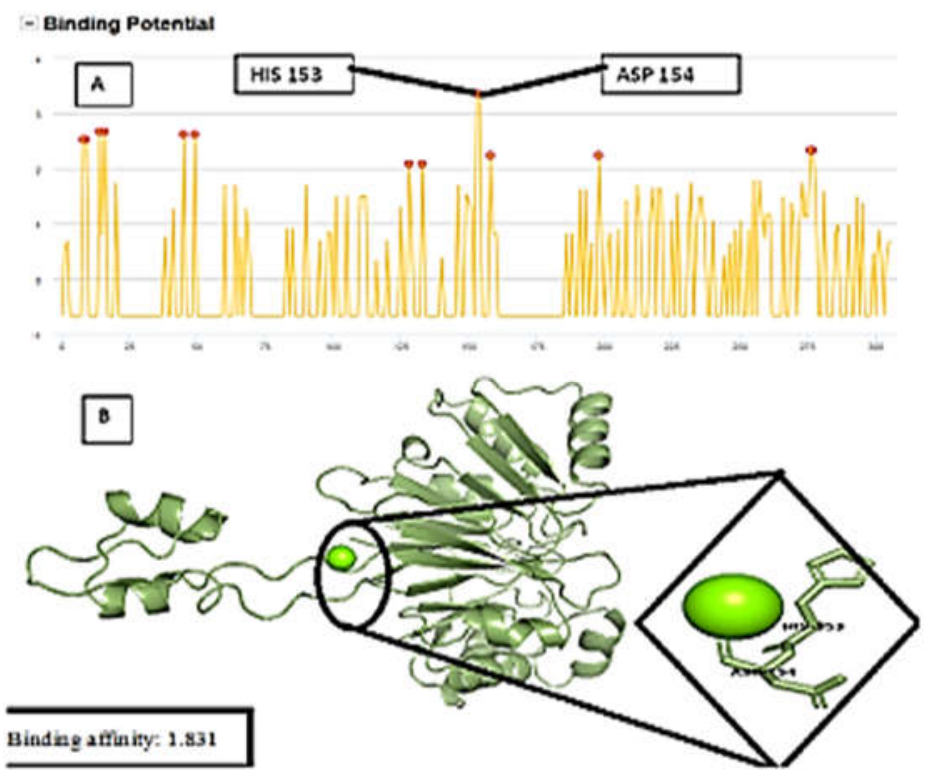

Figure 10: (a) Binding potential of each amino acid residues of ZiPD for $\mathrm{Mg}^{2+}$ and their corresponding binding affinities (b) Interacting residues within $\mathrm{ZiPD} \mathrm{Mg}^{2+}$ binding site with the corresponding binding potential 
$\mathrm{Mg}^{2+}$ is the most prevalent metal ions present in enzymes (Isani and Carpenè, 2014). This is due to the fact that most phosphate-containing substrates have magnesium as essential cofactor (Igunnu et al., 2014). It has been reported that ZiPD generates approximately equal amounts of exo- and endoribonucleolytic cleavage products in the presence of $\mathrm{Mg}^{2+}$ (Dutta et al., 2012). In this study, $\mathrm{Mg}^{2+}$ enhanced the affinity of ZiPD for bis-pNPP as indicated by the reduced $K_{m}$ but with a slightly reduced turnover rate indicating that the $\mathrm{Mg}^{2+}$ compete with the binuclear zinc for the substrate. The high binding potential of numerous amino acid residues also indicate that $\mathrm{Mg}^{2+}$ can bind at numerous sites other than the active site with very high binding affinity which can either positively or negatively modulate the enzyme activity. The increase in the substrate affinity of ZiPD for bis-pNPP can also be a mechanism by which the enzyme accommodates larger substrates since previous study demonstrated that $\mathrm{Mg}^{2+}$ ion stimulates the endoribonuclease activity of ZiPD to thymidine-5'-(paranitrophenyl) phosphate (TpNPP) substrate (Spath et al., 2007). It could be that $\mathrm{Mg}^{2+}$ favors the activity of ZiPD on a TpNPP substrate than on a bis-pNPP used in this study.

\section{Activation Effect and Binding Potential of $\mathrm{Zn}^{2+}$ on E. coli Zinc Phosphodiesterase Activity}

The effect of varying concentrations of $\mathrm{Zn}^{2+}$ on E. coli zinc phosphodiesterase (ZiPD) catalysed hydrolysis of bis-pNPP was investigated. $\mathrm{Zn}^{2+}$ increased ZiPD activity progressively from $200 \mu \mathrm{M}$ to $1500 \mu \mathrm{M}$, being the optimal concentration for ZiPD activity (Figure 11). There was 2-fold increase in ZiPD activity at this optimal concentration. However, there was a decrease in the activation effect from $1500 \mu \mathrm{M}$ to $3000 \mu \mathrm{M} \mathrm{Zn}{ }^{2+}$ (Figure 11). The Michealis-Menten curve and the Lineweaver-Burk plot for the substrate kinetics of ZiPD catalysed bis-pNPP hydrolysis both in the presence and absence of $\mathrm{Zn}^{2+}$ are shown in Figures 12a and $12 \mathrm{~b}$, respectively. $\mathrm{Zn}^{2+}$ at $1500 \mu \mathrm{M}$ increased the $V_{\max }$ by 2 -fold but reduced the $K_{m}$ by 4 -fold (Table 4). The binding affinity of each of the residues was calculated against $\mathrm{Zn}^{2+}$ and only residues with higher binding scores are predicted as $\mathrm{Zn}^{2+}$ binding residues as shown in the Figure 13a while the affinity binding of $\mathrm{Zn}^{2+}$ within the predicted $\mathrm{Zn}^{2+}$ binding sites reveals the interacting residues at optimum binding (Figure 13b).

$\mathrm{Zn}^{2+}$ is the second-most abundant metal ion in enzymes (Vogel et al., 2002; Arora et al., 2017). $\mathrm{Zn}^{2+}$ is very essential to life because of its inherent role in proteins which are involved in virtually all aspects of metabolisms, genetics and growth (Yan et al., 2001; Jaishankar et al., 2014). In this study, the activation effect of $\mathrm{Zn}^{2+}$ on ZiPD activity could be due to the increased maximum velocity and reduced $\mathrm{K}_{\mathrm{m}}$. $\mathrm{Zn}^{2+}$ has the highest binding affinity (2.636) for ZiPD which is not surprising since it is naturally found in this metalloenzyme. The consequence of higher binding of $\mathrm{Zn}^{2+}$ in comparison to other metal ions is revealed by its molecular interactions with more amino acids residues than other metal ions. Higher $\mathrm{Zn}^{2+}$ from $1500 \mu \mathrm{M}$ to $3000 \mu \mathrm{M}$ led to a decrease in the activity of the enzyme, which was accompanied with a precipitation of the protein. It is therefore in correlation with what was reported by Spath et al. (2007) that the inactivation is probably due to denaturation of ZiPD rather than to an enzymatic inhibition by zinc.

Structural stability is governed by hydrophilic and hydrophobic interactions between the backbone and side chains of individual amino acids in a protein. Hydrogen bonds and Van der Waals interactions are often the largest contributors to overall protein stability, but individually, salt bridges can contribute substantial energy to protein folding and stability (Vogt and Argos, 1997; Robinson et al., 2006; Feller, 2010). Salt bridge is the strongest electrostatic interactions in proteins. The salt bridge most often arises from the anionic carboxylate ( $\left.\mathrm{RCOO}^{-}\right)$of either aspartic acid or glutamic acid (Dougherty, 2006). Previous study has shown that six mutations at two catalytic residues, Glu-11 and Asp-20, within the active site of T4 lysozyme abolished or reduced enzymatic activity but increased thermal stability by 0.7-1.7 kcal.mol-1 (Shoichet et al., 1995). Thus, the highest binding affinity attributed to $\mathrm{Zn}^{2+}(2.636)$ in relation to $\mathrm{Co}^{2+}$ with the least binding affinity (1.773) may be due to its interaction with ASP68 and ASP212 and not necessarily the histidine residues since $\mathrm{Co}^{2+}$ interacted with two histidine residues (HIS45 and HIS49) as did $\mathrm{Zn}^{2+}$ (HIS69 and HIS270) (Table 5). Hence, the activation effect of $\mathrm{Zn}^{2+}$ on ZiPD activity might be due to the increased maximum velocity and reduced $\mathrm{K}_{\mathrm{m}}$. Furthermore, Mhaindarkar et al. (2018) demonstrated that loss of salt bridges due to mutation resulted in decrease in the substrate affinity and thus lead to an overall lower catalytic efficiency.

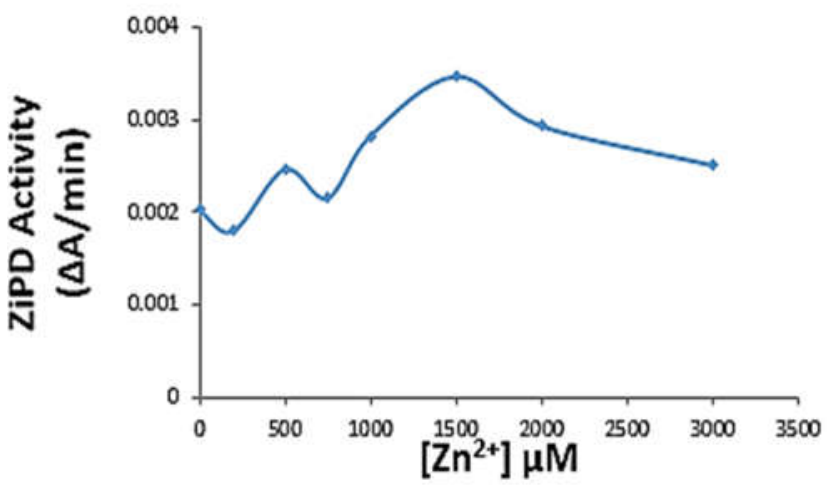

Figure 11: (a) Activation effect of $\mathrm{Zn}^{2+}$ on E. coli zinc phosphodiesterase catalysed hydrolysis of bis-para-nitrophenyl phosphate (Bis-pNPP). Each value is a mean of three independent assays.

A

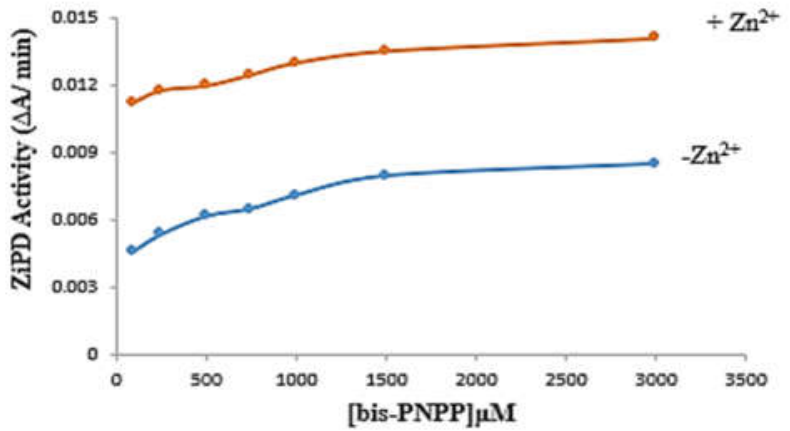




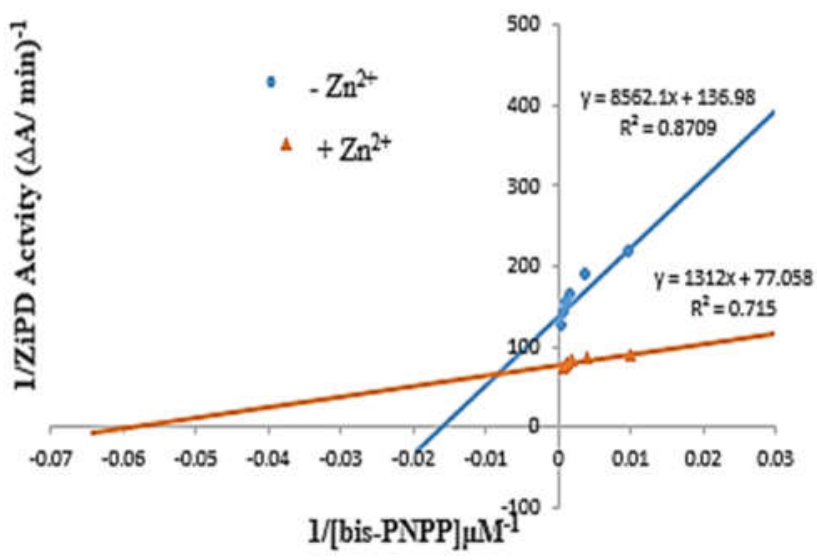

Figure 12: Substrate Kinetics of Zinc Phosphodiesterase catalysed Hydrolysis of bis-para-nitrophenyl phosphate in the presence and absence of $\mathrm{Zn}^{2+}$ (b) Michealis-Menten curve (c) Lineweaver-Burk plot. Each value is a mean of three independent assays.

Table 4: Kinetic parameters for E. coli zinc phosphodiesterase activities in the absence and presence of $1.5 \mathrm{mM}$ of $\mathrm{Zn}^{2+}$

\begin{tabular}{lcc}
\hline Reaction & $\mathbf{V}_{\max }(\boldsymbol{\Delta} \mathbf{A} / \mathbf{m i n})$ & $\mathbf{K}_{\mathbf{m}}(\boldsymbol{\mu} \mathbf{M})$ \\
\hline ZiPD- bis-pNPP & 0.007700 & 62.50 \\
ZiPD- bis-pNPP + 1.5 $\mathrm{mM}$ of $\mathrm{Zn}^{2+}$ & 0.01298 & 16.13 \\
\hline
\end{tabular}
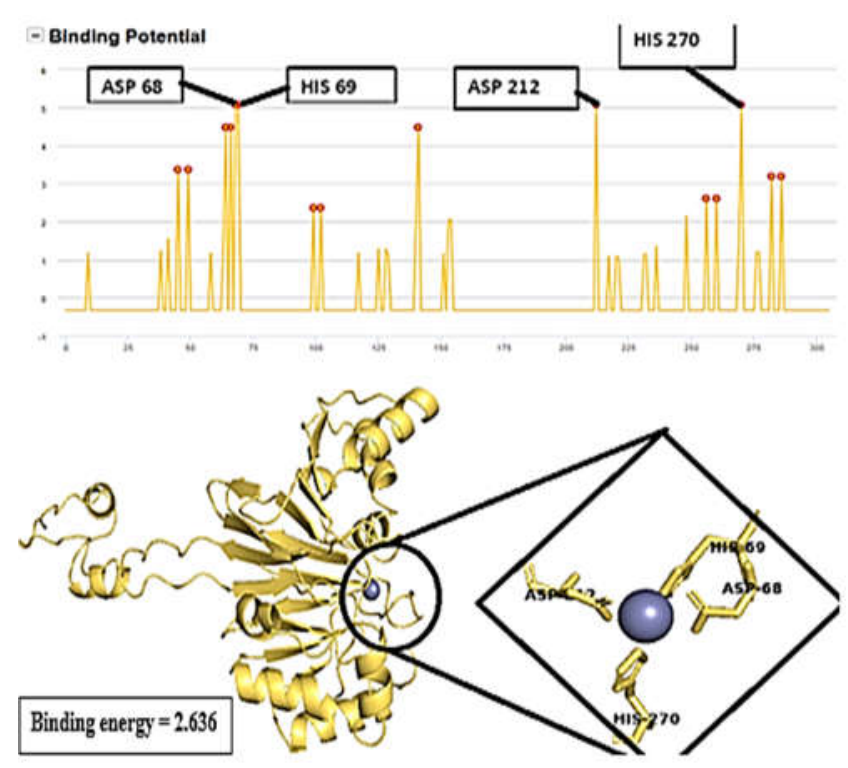

Figure 13: (A) Binding potential of each amino acid residues of ZiPD for $\mathrm{Zn}^{2+}$ and their corresponding binding affinities (B) Interacting residues within $\mathrm{ZiPD} \mathrm{Zn}^{2+}$ binding site with the corresponding binding potential
Table 5: Binding affinities of the studied metal ions in relation to zinc phosphodiesterase activity

\begin{tabular}{lll}
\hline $\begin{array}{l}\text { Ligand-ZiPD } \\
\text { complex }\end{array}$ & $\begin{array}{l}\text { Residues with the Highest } \\
\text { Affinity with Ligands }\end{array}$ & $\begin{array}{l}\text { Binding energy } \\
\text { (kcal/mol) }\end{array}$ \\
\hline $\mathrm{Mn}^{2+}$-ZiPD & ARG259, GLU260 & 1.795 \\
$\mathrm{Co}^{2+}-\mathrm{ZiPD}$ & HIS45, HIS49 & 1.773 \\
$\mathrm{Mg}^{2+}-\mathrm{ZiPD}$ & HIS153, ASP154 & 1.831 \\
$\mathrm{Zn}^{2+}$ ZiPD & HIS69, HIS270, & 2.636 \\
& ASP68, ASP212 \\
\hline
\end{tabular}

\section{Conclusion}

Our findings from this study showed that $\mathrm{Mn}^{2+}$ and $\mathrm{Zn}^{2+}$ ions are the most effective stimulatory ions of zinc phosphodiesterase with $\mathrm{Zn}^{2+}$ exerting the highest binding affinity for the enzyme. These findings may offer an insight into the metabolic roles of these ligands in zinc phosphodiesterase catalysis.

\section{Conflicts of interest}

The authors declare no conflict of interest.

\section{Author Contributions: \\ Conception: A.I. \\ Design: A.I.}

Execution: A. I, M.F.D, T.A, I.Y. J, O. O. L, O O.O, K.E.O, G.O.A, S.O M

Interpretation: A. I, M.F.D, T.A, I.Y. J, O. O. L, O O.O, K.E.O, G.O.A, S.O M Writing the paper: A. I, M.F.D, T.A, I.Y. J, K.E.O, G.O.A

\section{References}

Arise, R.O., Davies, F.F., Malomo, S.0., 2008, Independent and interactive effects of $\mathrm{Mg}^{2+}$ and $\mathrm{Co}^{2+}$ on some kinetic parameters of rat kidney alkaline phosphatase. Scientific Research and Essay, 3: 488494.

Arora, S., Jain, C.K., Lokhande, R.S., 2017, Review of Heavy metal contamination in Soil. International Journal of Environmental Sciences and Natural Resources, 3: 1-6.

Chih-Hao, L., Yu-Feng, L., Jau-Ji, L., Chin-Sheng, Y., 2012, Prediction of metal ion binding sites in proteins using the fragment transformation method. Public Library of Science One, 7 (6): e39252.

Daiyasu, H., Osaka, K., Ishino, Y., Toh, H., 2001, Expansion of the zinc metallo-hydrolase family of the beta-lactamase fold. Federation of European Biochemical Societies Letters, 503: 1-6.

de la Sierra-Gallay, I.L., Pellegrini, O., Condon. C., 2005, Structural basis for substrate binding, cleavage and allostery in the tRNA maturase RNase Z. Nature, 433: 657-661.

Dougherty, D. A., 2006, Modern Physical Organic Chemistry. Sausalito, CA: University Science Books. ISBN 978-1-891389-31-3.

Dutta, T., Deutscher, M.P., 2009, Catalytic properties of RNase 
BN/RNase Z from Escherichia coli: RNase BN is both an exo- and endoribonuclease. The Journal of Biological Chemistry, 284: 1542515431.

Dutta, T., Malhotra, A., Deutscher, M.P., 2012, Exoribonuclease and endoribonuclease activities of RNase BN/RNase Z both function in vivo. The Journal of Biological Chemistry, 42: 35747-35755.

Feller, G., 2010, Protein stability and enzyme activity at extreme biological temperatures. Journal of Physics: Condensed Matter, 22: 3231.

Green, R., Noller, H.M., 1997, Ribosomes and translation. Annual Review of Biochemistry, 66: 679-716.

Igunnu, A., Arise, R.O., Adebayo, J.O., Olorunniji, F.J., Malomo S.O., 2014, Catalytic cofactors $\mathrm{Mg}^{2+}$ and $\mathrm{Zn}^{2+}$ ions) influence the pattern of vanadate inhibition of the monoesterase activity of calf intestinal alkaline phosphatase. Biokemistri, 2: 36-42.

Isani, G., Carpenè, E., 2014, Metallothioneins, unconventional proteins from unconventional animals: A long journey from nematodes to mammals. Biomolecules, 4: 435-457.

Jaishankar, M., Tseten, T., Anbalagan, N., Mathew, B.B., Beeregowda, K.N., 2014, Toxicity, mechanism and health effects of some heavy metals. Interdisciplinary Toxicology, 7: 60-72.

Kelly, K.O., Deutscher, M.P., 1992, The presence of only one of five exoribonucleases is sufficient to support the growth of Escherichia coli. Journal of Bacteriology, 174: 6682-6684.

Mhaindarkar, D., Gasper, R., Lupilov, N., Hofmann, E., Leichert, L., 2018, "Loss of a conserved salt bridge in bacterial glycosyl hydrolase BgIMG1 improves substrate binding in temperate environments." Communications biology, 1 (1): 1-11.

Minagawa, A., Takaku, H., Ishii, R., Takagi, M., Shigeyuki, Y., Masayuki, $\mathrm{N}$., 2006, Identification by $\mathrm{Mn}^{2+}$ rescue of two residues essential for the proton transfer of tRNase $\mathrm{Z}$ catalysis. Nucleic Acids Research, 34: 3811-3818.

Minagawa, A., Takaku, H., Takagi, M., Nashimoto, M., 2004, A novel endonucleolytic mechanism to generate the CCA 3 ' termini of tRNA molecules in Thermotoga maritima. Journal of Biological Chemistry, 279: 15688-15697.

Morl, M., Marchfelder, A., 2001, The final cut. The importance of tRNA 3 '-processing. European Molecular Biology Organization Reports, 2: $17-20$.

Olorunniji, F.J., Igunnu, A., Adebayo, J.O., Arise, R.O., Malomo, S.O., 2007, Cofactor interactions in the activation of tissue non-specific alkaline phosphatase: Synergistic effects of $\mathrm{Zn}^{2+}$ and $\mathrm{Mg}^{2+}$ ions. Biokemistri, 2: 43-48.
Robinson-Rechavi, M., Alibés, A., Godzik, A., 2006, Contribution of electrostatic interactions, compactness and quaternary structure to protein thermostability: lessons from structural genomics of Thermotoga maritima. Journal of Molecular Biology, 356: 547-557.

Satya, P.G., 2018, Roles of metal ions in human health. MOJ Bioorganic and Organic Chemistry 2 (5): 221-224.

Shoichet, B.K., Baase, W.A., Kuroki, R., Matthews, B.W., 1995, "A relationship between protein stability and protein function." Proceedings of the National Academy of Sciences, 92 (2): $452-456$

Shumilina, E., Dobrovolska, O., del Conte, R., Holen, H.W., Dikiy, A., 2014, Competitive cobalt for zinc substitution in mammalian methionine sulfoxide reductase B1 over expressed in $E$. coli structural and functional insight. Journal of Biological Inorganic Chemistry, 19: 85-95.

Singh, V., Verma, K., 2018, Metals from cell to environment: Connecting Metallomics with other omics. Open Journal of Plant Science, 3 (1): 0114.

Spath B., Settele F., Schilling O.,| Igor D., Vogel A., Ingo F., MeyerKlaucke W., Marchfelder A., 2007, Metal Requirements and Phosphodiesterase Activity of tRNase Z Enzymes. Biochemistry, 46: 14742-14750.

Tavtigian, S.V., Simard, J., Teng, D.H., Abtin, V., Baumgard, M., Beck, A., Camp, N.J., Carillo, A.R., Chen, Y., Dayananth, P., Desrochers, M., Dumont, M., Farnham, J.M., Frank, D., Frye, C., Ghaffari, S., Gupte, J.S., Hu, R., Iliev, D., Janecki, T., Kort, E.N., Laity, K.E., Leavitt, A., Leblanc, G., McArthur-Morrison, J., Pederson, A., Penn, B., Peterson, K.T., Reid, J.E., Richards, S., Schroeder, M., Smith, R., Snyder, S.C., Swedlund, B., Swensen, J., Thomas, A., Tranchant, M., Woodland, A.M., Labrie, F., Skolnick, M.H., Neuhausen, S., Rommens, J., Cannon-Albright, L.A., 2001, A candidate prostate cancer susceptibility gene at chromosome 17. Nature Genetics, 27: 172-180.

Vogel, A., Schilling, O, Meyer-Klaucke, W., 2004, Identification of metal binding residues for the binuclear zinc phosphodiesterase reveals identical coordination as glyoxalase II. Biochemistry, 43: 1037910386.

Vogel, A., Schilling, O., Niecke, M., Bettmer, J., Meyer-Klaucke, W., 2002, ElaC encodes a novel binuclear zinc phosphodiesterase. Journal of Biological Chemistry, 277: 29078-29085.

Vogel, A., Schilling, O., Spa"th, B., Marchfelder, A., 2005, The tRNase Z family of proteins. Physiological functions, substrate specificity and structural properties. Journal of Biological Chemistry, 386: 1253-1264.

Vogt, G., Argos, P., 1997, Protein thermal stability: hydrogen bonds or internal packing? Folding and Design, 2: S40-S46.

Yan, W., Jang, G.F., Haeseleer, F., Esumi, N., Chang, J., Kerrigan, M., Zack, 
D.J., 2001, Cloning and characterization of a human $\beta, \beta$-carotene-15, $15^{\prime}$-dioxygenase that is highly expressed in the retinal pigment epithelium. Genomics, 2: 193-202. 